How to cite: Tașar, B., Unes, F., Varcin, H. (2019) Prediction of the Rainfall - Runoff Relationship Using NeuroFuzzy and Support Vector Machines. 2019 "Air and Water - Components of the Environment" Conference Proceedings, Cluj-Napoca, Romania, p. 237-246, DOI: 10.24193/AWC2019_24.

\title{
PREDICTION OF THE RAINFALL - RUNOFF RELATIONSHIP USING NEURO-FUZZY AND SUPPORT VECTOR MACHINES
}

\author{
Bestami TAȘAR ${ }^{1}$ 凹, Fatih UNES ${ }^{1}$, Hakan VARCIN ${ }^{1}$ \\ DOI: 10.24193/AWC2019_24
}

\begin{abstract}
Rainfall- Runoff relationship analyzes are essential for the protection of flood rooting, management of water resources and design of water structures. In this study, Neuro-Fuzzy (NF) and Support Vector Machines (SVM) methods are applied for Rainfall- Runoff prediction. Daily hydrological and seasonal data taken from Muskegon basin in USA were used for present study. 1397 daily data of rainfall, temperature and runoff from the study area were analyzed by NF and SVM methods. The results show that the SVM method lead to low errors and high determinations in the Rainfall-Runoff modeling. Models results are compared with daily observed data. SVM method can be used as an alternative to classical methods in Rainfall- Runoff prediction.
\end{abstract}

Keywords: Prediction, Rainfall, Runoff, Support vector machines, Neuro-fuzzy.

\section{INTRODUCTION}

For many years hydrology engineers have needed to achieve runoff forecast for several purposes such as water supply, flood control, irrigation, drainage, water quality and energy production. For this reason, they have tried to understand the relationship between rainfall and runoff. In hydrology and water resources engineering, accurate estimation of the rainfall and runoff relationship on a drainage basin is an important issue. This prediction can be made for a short period of time, such as single periods or torrential events, or to cover long periods such as monthly or annually. However, the change in local and regional characteristics makes it difficult to identify. The analysis is designed with the aid of mathematical and statistical models, leading to a more accurate analysis and trying to estimate the past parameters of the hydrological cycle. In this hydrological cycle, the rainfall-runoff relationship has particular importance. Artificial intelligence was applied in hydraulic events and water resource management by many researchers (Nivesh et al., 2018; Demirci et al., 2015a, 2015b, 2016, 2017, 2018a, 2018b; Kaya et al., 2016, 2017, 2018; Tasar et al., 2017, 2018; Demirci and Baltaci, 2013; Unes, 2010a, 2010b; Unes and Demirci, 2015; Unes et al., 2015, 2017a, 2017b, 2018a, 2018b, 2018c).

\footnotetext{
1 Iskenderun Technical University, Civil Engineering Department, Iskenderun, Turkey
} bestami.tasar@iste.edu.tr fatih.unes@iste.edu.tr hakan.varcin@iste.edu.tr 
When the studies are examined, estimations can be made about the operation of watershed and water resources by using hydrological and climatic data. Gokbulak et al. (2015) used for rainfall-runoff modeling, artificial neural networks (ANN) with feed forward back propagation.

Shoaib et al. (2016) investigated the potential of hybrid Wavelet Co-Active Neuro Fuzzy Inference System (WCANFIS) models for rainfall-runoff simulations in China. Mishra and Karmakar (2018) examined the backpropagation neural network model by using the rainfall-runoff data. Granata et al. (2016) have used support vector machine approach (SVM) for rainfall-runoff modeling. The purpose of this study is to investigate the rainfall-runoff prediction performance of NeuroFuzzy (NF) and Support Vector Machine (SVM) methods.

\section{DATA AND METHODS}

\subsection{Data used}

Muskegon river basin is selected as study area in this paper. The main stream is $348 \mathrm{~km}$ long and drains an area of $6100 \mathrm{~km}^{2}$ in Muskegon river basin. 1397 daily data for water temperature, runoff and rainfall were used. Data set is collected between 2014 and 2018 years by USGS. Data belongs to Muskegon River basin with station number 04121970. In Figure 1, view of Muskegon river basin is given.

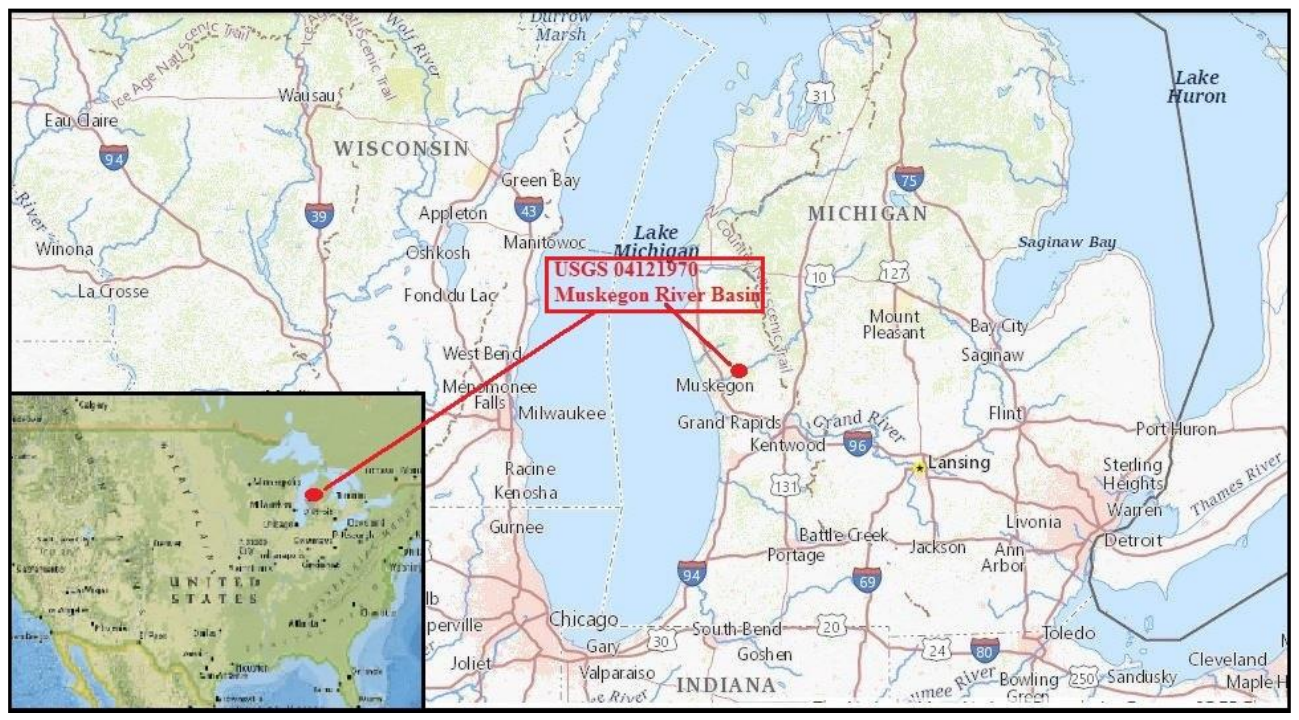

Fig. 1. General view of the Muskegon River Basin (USGS)

\subsection{Methods}

In this paper, Neuro-Fuzzy (NF) and Support Vector Machine (SVM) methods were used to obtain rainfall-runoff estimation model. Data belongs to Muskegon River with station number 04121970. 


\subsubsection{NF Method}

Neuro-Fuzzy (NF) model, first described by Zadeh (1965), is based on fuzzy cluster logic. NF system works by a learning algorithm derived from neural network functional rules. The parameters of the fuzzy inference system are determined by the neural network learning algorithms. In a fuzzy rule-based system, different analysis methods such as Sugeno can be applied. NF with Sugeno type works according to "If-Then" rule and the NF structure uses the Sugeno-Fuzzy rules. According to "IfThen" rule, if $\mathrm{x}$ is $\mathrm{A}_{1}$ then $\mathrm{y}$ is $\mathrm{B}_{1}$ where $\mathrm{A}_{1}$ and $\mathrm{B}_{1}$ are linguistic values defined by fuzzy sets. It is possible to introduce fuzzy systems that logical models which is consisted of "If-Then" rules and membership functions. For more information, researchers can access Jang [30].

\subsubsection{SVM Method}

Support Vector Machine (SVM) is a method of learning found by Cortes and Vapnik (1995) for solving the classification and regression problems. It is likely that classification of variables on a plane by drawing a boundary between them. The boundary which is drawn between variables must be as far as possible to each variable. SVM provides to define how to draw this boundary between variables group. In SVM, the Kernel method greatly increases machine learning in nonlinear data. The process of an SVM estimator (y) can be expressed as:

$$
\mathrm{y}=\left(\mathrm{K}_{\mathrm{xi}} \cdot \mathrm{W}_{\mathrm{jk}}\right)+\mathrm{b}
$$

where

the Kernel function is $K_{x i}, b$ is bias term of SVM network and

$W_{j k}$ is called as the weight vector.

$\mathrm{K}_{\mathrm{x}}$ and $\mathrm{W}$ show Lagrange multipliers. $K_{x i}$ is a nonlinear function that maps the input vectors into a high-dimensional feature space. The inner product of the inputs is calculated by using kernel functions. Lagrange multipliers show the weights the non-linear Poly Kernel functions used in this study. Details about SVM can be found in Vapnik (1999) and Haykin (1999).

\section{RESULTS AND DISCUSSIONS}

In this study, the results of Neuro-fuzzy (NF1, NF2) and Support Vector Machine (SVM1, SVM2) were compared according to the following statistical criteria. In the model SVM1 and NF1, daily water temperature $(T)$, rainfall $(\mathrm{P})$, runoff time series $\left(\mathrm{Q}_{\mathrm{t}-1}\right)$, parameters were used for runoff modeling. In addition, in the model SVM2 and NF2, runoff modeling was performed with water temperature $(\mathrm{T})$, rainfall $(\mathrm{P})$, rainfall time series $\left(\mathrm{P}_{\mathrm{t}-1}\right)$, runoff time series $\left(\mathrm{Q}_{\mathrm{t}-1}\right)$. In this study, 350 of the 1397 daily temperature and rainfall-runoff data were used for testing, while the remaining 1047 were used for training. In the modeling, Statistical criteria such as Determination coefficient $\left(\mathrm{R}^{2}\right)$, Mean Absolute Error (MAE) and Root Mean Square Error (RMSE) were calculated and the results were interpreted by two evaluations for each model. 
The $\mathrm{R}^{2}$ measures the strength of the correlation between the predicted and real values. The fact that the linear relationship is 1 indicates that the result is very close. The MAE and RMSE measure the accuracy by continuously calculating the mean size of the errors in the estimation without taking into account the aspects of the variables. MAE and RMSE are used to diagnose the possibility of errors. $\mathrm{R}^{2}$, MAE and RMSE calculations were determined according to below equations:

$\mathrm{MAE}=\frac{1}{\mathrm{n}} \sum_{\mathrm{j}=1}^{\mathrm{n}}\left|\mathrm{Q}_{\text {meauserement }}-\mathrm{Q}_{\text {predicted }}\right| \quad$ Q: runoff, $\mathrm{m}^{3} / \mathrm{s}$

$\mathrm{RMSE}=\sqrt{\frac{1}{\mathrm{n}} \sum_{\mathrm{i}=1}^{\mathrm{n}}\left(\mathrm{Q}_{\text {measurement }}-\mathrm{Q}_{\text {predicted }}\right)^{2}} \quad$ Q: runoff, $\mathrm{m}^{3} / \mathrm{s}$

MAE, RMSE and $\mathrm{R}^{2}$ statistics are calculated for comparison of methods used. SVM and NF results are given in Table 1.

Table 1. Statistical results of NF and SVM models

\begin{tabular}{|c|c|c|c|c|}
\hline MODELS & $N F 1$ & $S V M 1$ & $N F 2$ & SVM2 \\
\hline INPUTS & $\mathrm{T}, \mathrm{P}, \mathrm{Q}_{\mathrm{t}-1}$ & $\mathrm{~T}, \mathrm{P}, \mathrm{Q}_{\mathrm{t}-1}$ & $\mathrm{~T}, \mathrm{P}, \mathrm{P}_{\mathrm{t}-1}, \mathrm{Q}_{\mathrm{t}-1}$ & $\mathbf{T}, \mathbf{P}, \mathbf{P}_{\mathrm{t}-1}, \mathbf{Q}_{\mathrm{t}-1}$ \\
\hline MAE & 5.86 & 5.22 & 5.56 & $\mathbf{4 . 8 8}$ \\
\hline RMSE & 18.05 & 11.94 & 16.12 & $\mathbf{1 0 . 2 6}$ \\
\hline $\mathbf{R}^{2}$ & 0.77 & 0.89 & 0.81 & $\mathbf{0 . 9 2}$ \\
\hline
\end{tabular}

T: water temperature, $P$ : rainfall, $Q$ : runoff

The most appropriate result among the models where data is used, as shown in Table 1, is given by SVM2 model. Distribution and scatter graphs of NF1 model are shown in Figure 2 and 3 below, respectively.

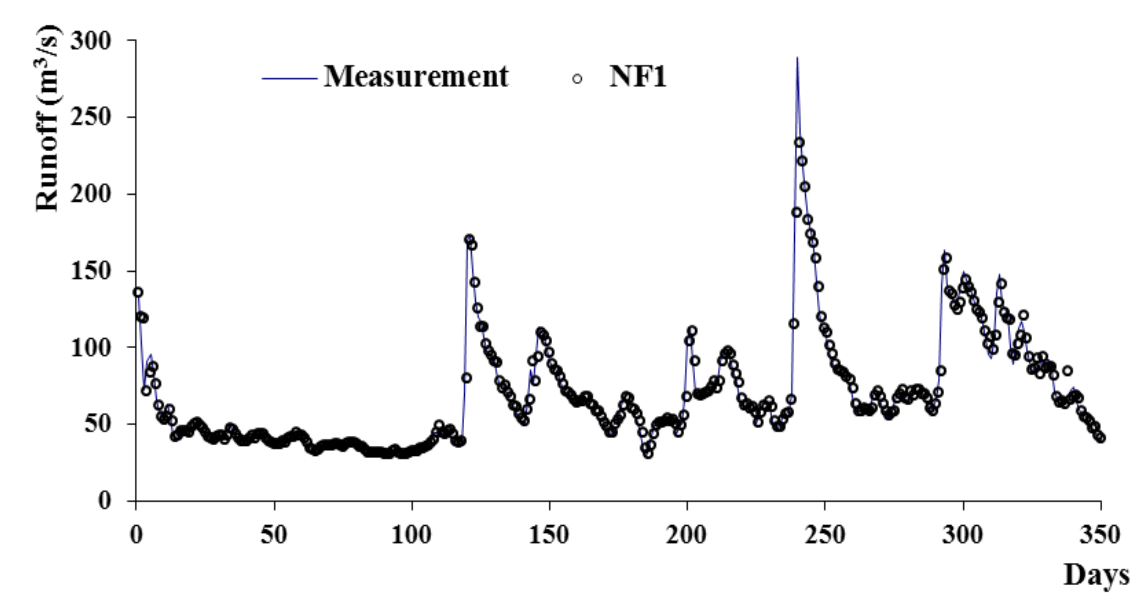

Fig. 2. NF1 model distribution charts for Muskegon River test data 


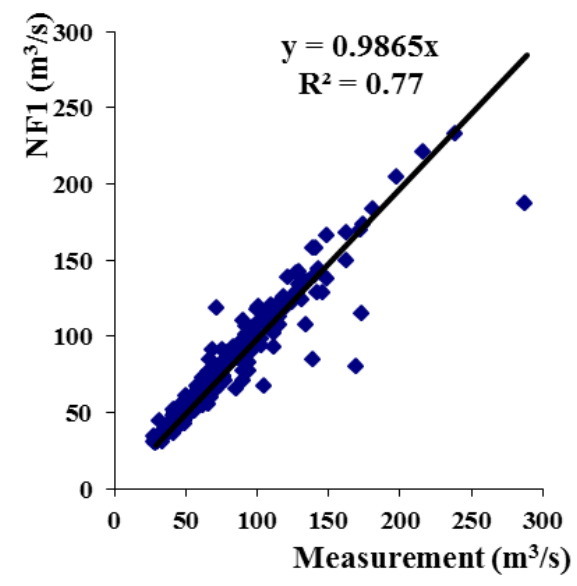

Fig. 3. NF1 model scatter charts for Muskegon River test data

Figure 2 and 3 show the performance of NF1 model. Determination coefficient for NF1 model is 0.77 . Distribution and scatter graphs of SVM1 model are shown in Figure 4 and 5 below, respectively.

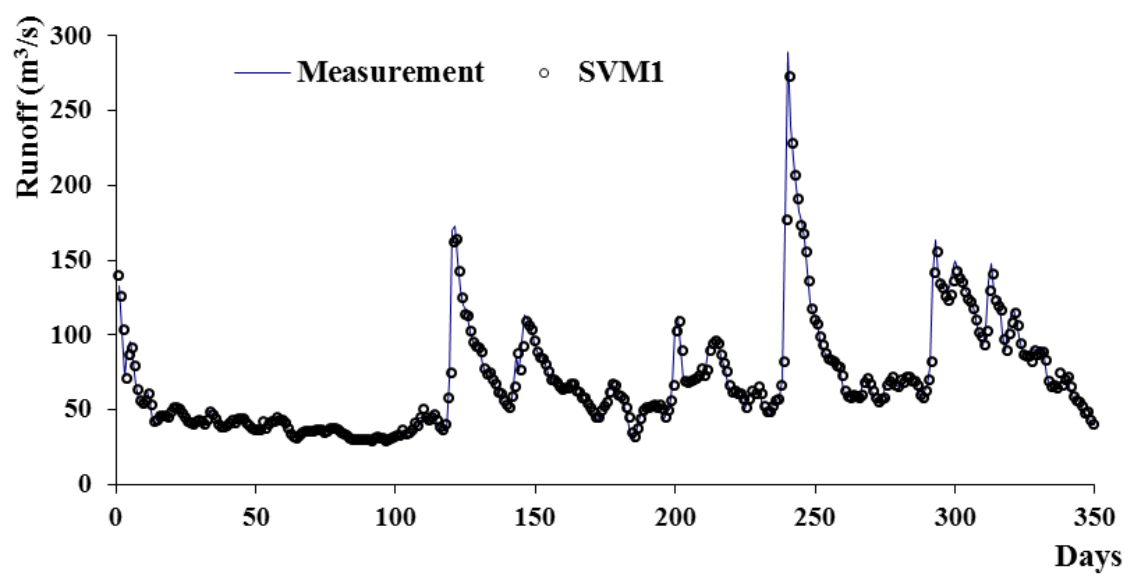

Fig. 4. SVM1 model distribution charts for Muskegon River test data

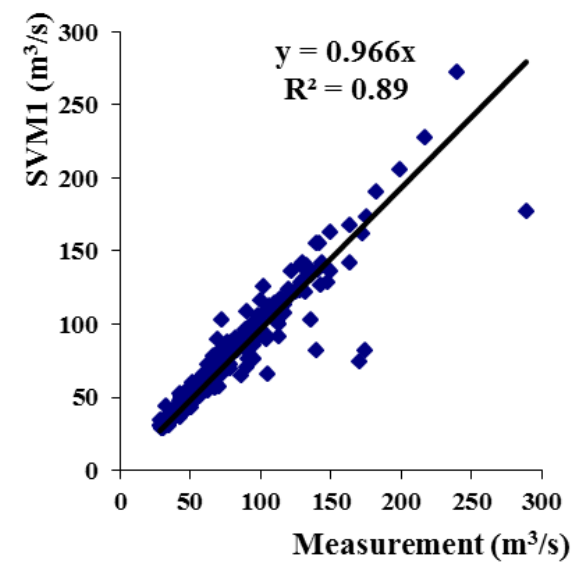

Fig. 5. SVM1 model scatter charts for Muskegon River test data 
Figure 4 and 5 show the performance of SVM1 model. Determination coefficient for SVM1 model is 0.89 . When NF1 and SVM1 models were examined, it was observed that SVM1 model gave better results. Distribution and scatter graphs of NF2 model are shown in Figure 6 and 7 below, respectively.

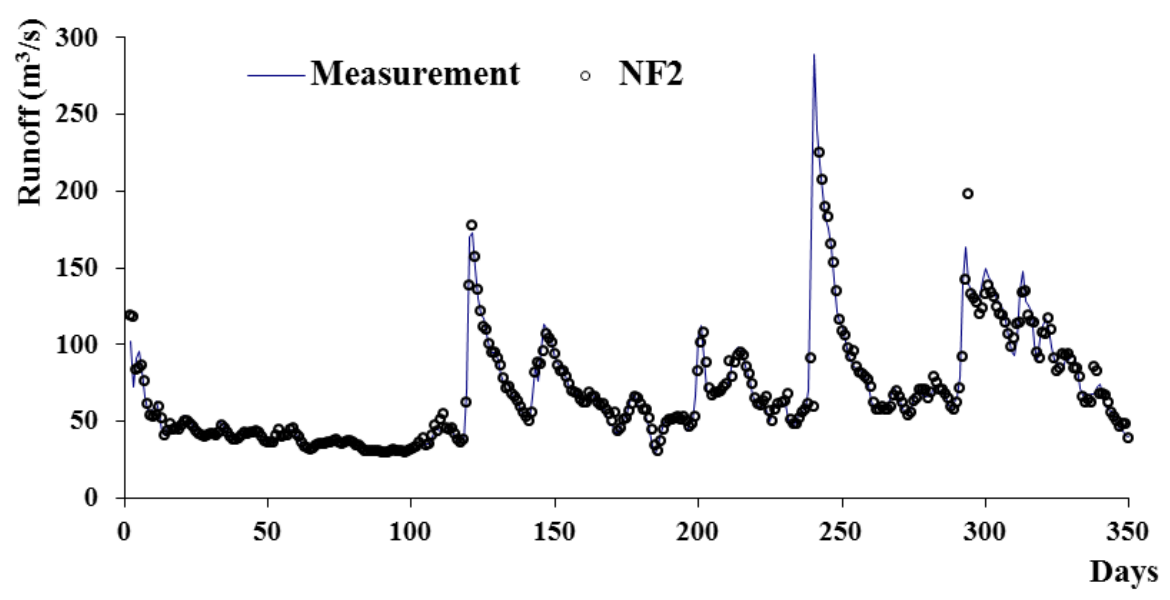

Fig. 6. NF2 model distribution charts for Muskegon River test data

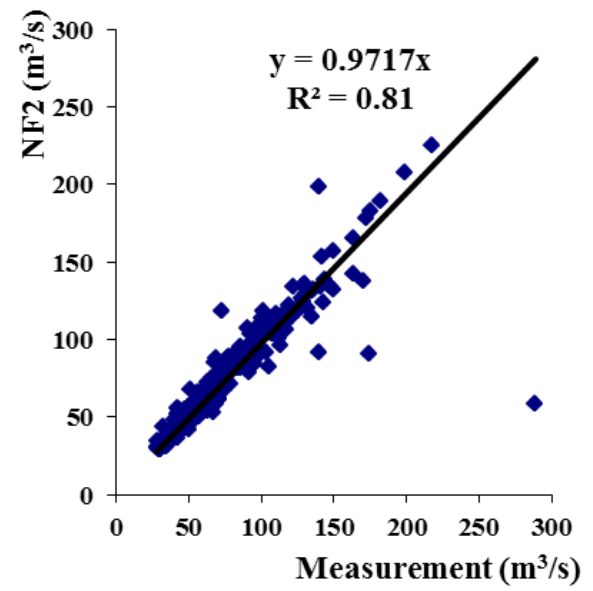

Fig. 7. NF2 model scatter charts for Muskegon River test data

Figure 6 and 7 show the performance of NF2 model. Determination coefficient for NF2 model is 0.81 . Distribution and scatter graphs of SVM2 model are shown in Figure 8 and 9 below, respectively.

Figure 8 and 9 show the performance of SVM2 model. Determination coefficient for SVM2 model is 0.92 . When NF2 and SVM2 models were examined, it was observed that SVM2 model gave better results.

According to Table 1 and distribution-scatter charts, it is observed that SVM models have good results for the test data. The good results can be expressed by a high coefficient of determination $\left(\mathrm{R}^{2}\right)$ and a low error amount (RMSE, MAE). Accordingly, 
the best estimation is given by the SVM2 model with the highest value of correlation $\left(\mathrm{R}^{2}\right.$ $=0.92)$ and the lowest error value $-\operatorname{RMSE}\left(10.26 \mathrm{~m}^{3} / \mathrm{s}\right)$ and $\operatorname{MAE}\left(4.88 \mathrm{~m}^{3} / \mathrm{s}\right)$.

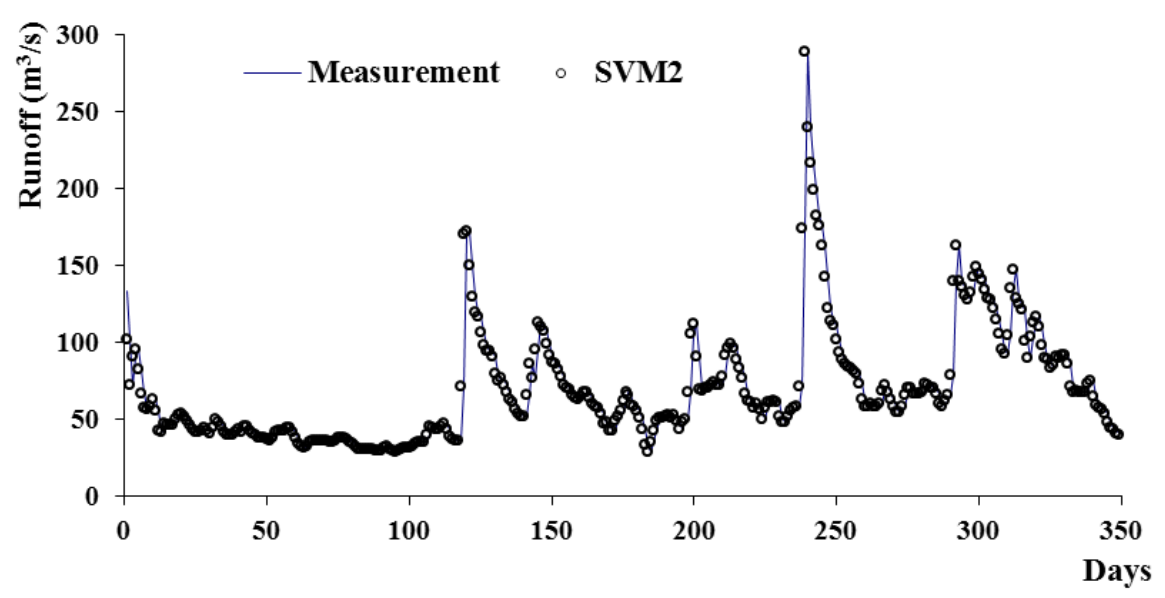

Fig. 8. SVM2 model distribution charts for Muskegon River test data

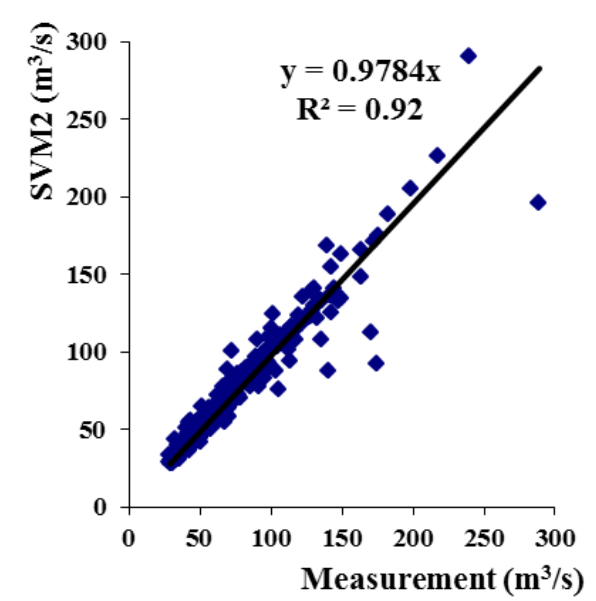

Fig. 9. SVM2 model scatter charts for Muskegon River test data

In addition, comparing the two NF models highlights that NF2 models is better $\left(\mathrm{R}^{2}=0.81, \mathrm{RMSE}=16.12 \mathrm{~m}^{3} / \mathrm{s}\right.$ and $\left.\mathrm{MAE}=5.56 \mathrm{~m}^{3} / \mathrm{s}\right)$. As a result of this study, the use SVM method for modeling the relationship between rainfall-runoff, (which is one of the artificial intelligence methods) can be presented as an alternative to traditional methods.

\section{CONCLUSIONS}

In this study, Neuro-Fuzzy (NF) and Support Vector Machine (SVM) methods were used to obtain the rainfall-runoff estimation model of the Muskegon River. 
Water temperature, rainfall, runoff time series and runoff modeling was performed for the model SVM1 and NF1. In addition, in the model SVM2 and NF2, runoff modeling was performed with water temperature, rainfall, rainfall time series and runoff time series. SVM model results are compared with the measured runoff quantity and the results of the NF method.

It has been observed that the NF method gives quite accurate results in the solution of the problem. However, comparison of SVM and NF methods show that SVM has better estimation performance for rainfall-runoff relation.

As a result, the low amount of error (MAE, RMSE) ratios and high determination $\left(\mathrm{R}^{2}\right)$ provided the desired performance in SVM methods. The reason for the high correlation of the SVM method is that determine the relationship between rainfall and runoff.

Support Vector Machine (SVM) have been found to be a model that can be applied in the estimation of the runoff occurring with rainfall, in the studies which water planning is required and in determining the water level changes. As a final result, it is understood that SVM can be used for hydrological modelling which is necessary for water resources management and planning future requirements.

\section{ACKNOWLEDGEMENTS}

In this paper, hydrological data were obtained from USGS (United States Geological Survey). The authors wish to thank the USGS technical team who are involved in measuring and transferring hydrological data.

\section{REFERENCES}

1. Cortes, C., Vapnik, V. (1995), Support vector networks, Machine Learning, 20,1-25.

2. Demirci, M., Baltaci, A. (2013), Prediction of suspended sediment in river using fuzzy logic and multilinear regression approaches. Neural Computing and Applications, 23(1), 145-151.

3. Demirci, M., Unes, F., Saydemir, S. (2015a), Suspended sediment estimation using an artificial intelligence approach. Sediment Matters, Springer, 83-95.

4. Demirci, M., Unes, F., Aköz, M.S. (2015b), Prediction of cross-shore sandbar volumes using neural network approach. Journal of Marine Science and Technology, 20(1), 171-179.

5. Demirci, M., Unes, F., Akoz, M.S. (2016), Determination of nearshore sandbar crest depth using neural network approach. International Journal of Advanced Engineering Research and Science, 3(12), 133-140.

6. Demirci, M., Unes, F., Kaya, Y.Z., Mamak, M., Tasar, B., Ispir, E. (2017), Estimation of Groundwater Level Using Artificial Neural Networks: a Case Study of HatayTurkey. 10th International Conference "Environmental Engineering".

7. Demirci, M., Tasar, B., Kaya, Y.Z., (2018), Estimation of Groundwater Level Fluctuations Using Neuro-Fuzzy and Support Vector Regression Models. Int. J. Adv. Eng. Res. Sci. 5, 206-211. doi:10.22161/ijaers.5.12.29 
8. Demirci, M., Unes, F., Kaya, Y.Z., Tasar, B., Varcin, H. (2018), Modeling of Dam Reservoir Volume Using Adaptive Neuro Fuzzy Method. Air and Water Components of the Environment Conference, DOI: 10.24193/AWC2018_18

9. Gokbulak, F., Şengönül, K., Serengil, Y., Yurtseven, İ., Özhan, S., Cigizoglu, H.K., Uygur, B. (2015), Comparison of rainfall-runoff relationship modeling using different methods in a forested watershed. Water resources management, 29(12), 4229-4239.

10. Granata, F., Gargano, R., de Marinis, G. (2016), Support vector regression for rainfall-runoff modeling in urban drainage: A comparison with the EPA's storm water management model. Water, 8(3), 69.

11. Haykin, S. (1999), Multilayer perceptrons. Neural networks: a comprehensive foundation, 2, 135-155.

12. Jang, J.S. (1993), ANFIS: adaptive-network-based fuzzy inference system. IEEE transactions on systems, man, and cybernetics, 23(3), 665-685.

13. Kaya, Y.Z., Mamak, M., Unes, F., (2016), Evapotranspiration Prediction Using M5T Data Mining Method. Int. J. Adv. Eng. Res. Sci. 3, 225-229. doi:10.22161/ijaers/3.12.40

14. Kaya, Y.Z., Mamak, M., Ünes, F., Demirci, M., (2017) Evapotranspiration Prediction Using M5T Method and Ritchie Equation for St. Johns, FL, USA, in: Proceedings of 10th International Conference "Environmental Engineering." VGTU Technika, pp. 27-28. doi:10.3846/enviro.2017.024

15. Kaya, Y.Z., Unes, F., Demirci, M., Tasar, B., Varcin, H. (2018), Groundwater Level Prediction Using Artificial Neural Network and M5 Tree Models. Air and Water Components of the Environment Conference, DOI: 10.24193/AWC2018_23

16. Mishra, P.K., Karmakar, S. (2018), Performance of optimum neural network in rainfall-runoff modeling over a river basin. International Journal of Environmental Science and Technology, 1-14.

17. Nivesh, S., Kumar, P., Sawant, P., Verma, R. (2018), Application of Fuzzy Logic and Statistical Approaches for Estimation of Suspended Sediment Concentration. Int. J. Curr. Microbiol. App. Sci, 7(2), 3716-3733.

18. Shoaib, M., Shamseldin, A.Y., Melville, B.W., Khan, M.M. (2014), Hybrid wavelet neuro-fuzzy approach for rainfall-runoff modeling. Journal of Computing in Civil Engineering, 30(1), 04014125.

19. Tasar, B., Unes, F., Demirci, M., Kaya, Y.Z. (2018), Yapay sinir ağları yöntemi kullanılarak buharlaşma miktarı tahmini. DÜMF Mühendislik Dergisi, 9(1), 543551.

20. Tasar, B., Kaya, Y.Z., Varçin, H., Unes, F., Demirci M. (2017), Forecasting of suspended sediment in rivers using artificial neural networks approach. International Journal of Advanced Engineering Research and Science, 4(12), 79-84.

21. Unes, F. (2010a), Dam reservoir level modeling by neural network approach: a case study. Neural Network World, 4(10), 461.

22. Unes, F. (2010b), Prediction of density flow plunging depth in dam reservoirs: an artificial neural network approach. Clean-Soil, Air, Water, 38(3), 296-308.

23. Unes, F., Demirci, M. (2015), Generalized Regression Neural Networks For Reservoir Level Modeling. International Journal of Advanced Computational Engineering and Networking, 3, 81- 84.

24. Unes, F., Yildirim, S., Cigizoglu, H.K., Coskun, H. (2013), Estimation of dam reservoir volume fluctuations using artificial neural network and support vector regression. Journal of Engineering Research, 1(3), 53-74. 
25. Unes, F., Demirci, M., Kişi, Ö. (2015), Prediction of millers ferry dam reservoir level in USA using artificial neural network. Periodica Polytechnica Civil Engineering, 59(3), 309-318.

26. Unes, F., Gumuscan, F.G., Demirci, M. (2017), Prediction of Dam Reservoir Volume Fluctuations Using Adaptive Neuro Fuzzy Approach. EJENS, 2(1), 144-148.

27.Unes, F., Kaya, Y.Z., Mamak, M., Demirci, M. (2017), Evapotranspiration Estimation Using Support Vector Machines and Hargreaves-Samani Equation for St. Johns, FL, USA. 10th International Conference "Environmental Engineering”, Doi: 10.3846/enviro.2017.094

28. Unes, F., Bölük, O., Kaya, Y.Z., Tasar, B., Varçin, H. (2018a), Estimation of RainfallRunoff Relationship Using Artificial Neural Network Models for Muskegon Basin. Int. J. Adv. Eng. Res. Sci., 5(12), 198-205. http://dx.doi.org/10.22161/ijaers.5.12.28

29. Üneş, F., Doğan, S., Taşar, B., Kaya, Y., Demirci, M. (2018b), The Evaluation and Comparison of Daily Reference Evapotranspiration with ANN and Empirical Methods. Natural and Engineering Sciences, 3(3), Supplement, 54-64.

30. Üneş, F., Demirci, M., Mertcan, Z., Taşar, B., Varçin, H., Ziya, Y. (2018c). Determination of Groundwater Level Fluctuations by Artificial Neural Networks. Natural and Engineering Sciences, 3(3), Supplement, 35-42.

31. USGS.gov | Science for a changing world [WWW Document], n.d. URL https://www.usgs.gov/

32. Vapnik, V.N. (1999), An overview of statistical learning theory. IEEE transactions on neural networks, 10(5), 988-999.

33. Zadeh, L.A. (1965), Fuzzy Sets. Journal of Information Control, 8(3), 338-353. 